\title{
Maternal morbidity associated with in utero transfer
}

\author{
T D R Ryan, G Mervyn Kidd
}

TABLE I - Reasons for in utero transfer in pregnant women admitted to Liverpool Maternity Hospital over two years

Group 1

Threatened or established uncomplicated preterm labour

$$
\text { Group } 2
$$

Pre-eclampsia

Evidence of fetal compromise 25 Antepartum haeme 21 Remediabe felat anhage Remediable fetal anomaly Suspected ruptured uterus Bacterial endocarditis

Total

Abstract

Objective-To determine the extent of maternal morbidity associated with in utero transfer.

Design-Retrospective study of 190 consecutive cases over two years.

Setting-Liverpool Maternity Hospital.

Patients-190 Pregnant women were transferred to the hospital under the in utero transfer arrangements from district general hospitals both within and outside the Mersey region. The women admitted were divided into two categories: those in threatened or established uncomplicated preterm labour and those who may or may not have been in threatened or established preterm labour but who had coexisting complicating factors affecting the mother or fetus, or both.

Interventions-Planned delivery of the fetus if indicated and arrangements for appropriate postpartum care of the mother.

Main outcome measure-Assessment of the progress of labour and, if appropriate, resuscitation of the mother.

Results - Women who were transferred with no coexisting disease (124) had relatively uncomplicated deliveries whereas those transferred with coexisting diseases (66) exhibited considerable morbidity and 17 of these required prolonged intensive monitoring after delivery.

Conclusions - In utero transfer in healthy mothers may have benefits for babies born very prematurely. If mothers have coexisting disease, however, the desirability of transfer should be reviewed urgently in the light of the considerable maternal morbidity associated with these problems. In these cases transfer may introduce an additional hazard.

\section{Introduction}

In utero transfer has become established in many centres in the United Kingdom as a means of providing sick, preterm neonates with immediate access to intensive care facilities, especially ventilatory support. Such transfer relieves the district general hospital of the problems concerned in dealing with these difficult cases. As pointed out by Chiswick, ${ }^{1}$ however, many of the babies who are transferred in utero do not require ventilatory support and use up valuable resources at the central unit. This view was reinforced by Cooke, ${ }^{2}$ who suggested that most fetuses do not need to be transferred and that there is no statistical evidence available for the United Kingdom to suggest any advantage for in utero rather than postnatal transfer of sick neonates. Low birthweight babies with respiratory problems may fare better if delivered in a unit with intensive care facilities for neonates, but to date no appreciable reductions in neonatal mortality or morbidity have been shown to result from in utero transfer. ${ }^{3-10}$

Often the mothers who are transferred have various

Dr Ryan. diseases related to pregnancy, and caution has been urged in selecting such patients for transfer. ${ }^{511}$ In recent years this hospital has experienced a steady increase in the number of babies transferred in utero, which has been paralleled by a rise in maternal morbidity among the mothers transferred. This has produced considerable difficulties for all of the staff in the unit.

We reviewed the number of in utero transfers over two years and the outcome for mothers and neonates to establish the extent of the problem and determine whether any specific groups of women were at particular risk of developing problems subsequent to transfer.

\section{Patients and methods}

Over two years from June 1986, 190 patients were transferred to the hospital under the in utero transfer arrangements, which meant that virtually all of the patients referred were accepted for admission. The patients were transferred from 20 different district general hospital obstetric units from both within Mersey region and beyond. The distance of transfer ranged from over $48 \mathrm{~km}$ in 44 cases $(23 \%)$ to only $3 \mathrm{~km}$. One patient arrived by emergency air transfer; most were transferred without medical staff escort.

\section{REASONS FOR TRANSFER}

The patients admitted to the hospital were divided into two categories (table I). Group 1 comprised 124 women in threatened or established uncomplicated preterm labour. The mean gestational age at the time of referral in this group was 28.3 weeks. Group 2 comprised 66 patients who may or may not have been in a state of threatened or established preterm labour but who had coexisting complicating factors affecting the mother or the fetus, or both; these patients had a mean gestational age at the time of referral of $29 \cdot 0$ weeks.

Of the 190 fetuses, only three had a gestational age in excess of 34 weeks at the time of transfer. All of these had potentially remediable surgical anomalies, and transfer was undertaken so that they could be near a suitable paediatric surgical unit. Transfer was not undertaken solely in the interests of the mother's condition in any of the cases. In each instance it was the perceived threat to the fetus that precipitated transfer.

\section{TREATMENT BEFORE TRANSFER}

Of the 124 women in group $1,21(17 \%)$ were treated with $\beta$ adrenoceptor agonists before arrival at the hospital in an attempt to suppress preterm labour. In group 2, $23(35 \%)$ of the 66 women had treatment before arrival to control coexisting diseases; these were predominantly women with pre-eclampsia. At the time of transfer 21 of the 25 women with pre-eclampsia were being treated with antihypertensive drugs or anticonvulsants, or both; one woman with antepartum 


\begin{tabular}{lrr}
\hline & Group 1 & Group 2 \\
\hline$<1$ h & $20(16)$ & $12(18)$ \\
1 h to 1 day & $59(48)$ & $33(50)$ \\
1 day to & & \\
$\quad$ 1 week & $28(23)$ & $9(14)$ \\
$>$ 1 week & $8(7)$ & $7(11)$ \\
Undelivered & $9(7)$ & $5(8)$ \\
\hline Total & 124 & 66 \\
\hline
\end{tabular}

TABLE II-Intervals from admission to delivery in 190 pregnant women transferred to Liverpool Maternity Hospital.

Figures are numbers

(percentages) of women

haemorrhage was having a blood transfusion; and a diabetic patient was receiving an intravenous infusion of insulin.

\section{TREATMENT AFTER TRANSFER (BEFORE DELIVERY)}

After admission to the hospital most women with uncomplicated preterm labour were too far advanced in labour for any action to be taken other than for their delivery to be arranged. In 40 of these cases expectant management was adopted, and in 27 of them treatment with antibiotics was instigated as a prophylaxis against infection of ruptured membranes.

The patients with coexisting diseases required much more active management. All 25 women with pre-eclampsia were treated with antihypertensive drugs and three women with antepartum haemorrhage had immediate blood transfusion.

\section{Results}

\section{ADMISSION TO DELIVERY INTERVALS}

Table II gives the intervals from admission to delivery. More than three quarters of the patients had delivered within 48 hours after admission, and an appreciable number of women in group 1 were fortunate to deliver in hospital rather than in the ambulance transporting them. In group 2, 17 of the 25 patients transferred with pre-eclampsia were delivered by caesarean section less than four hours after admission. In those patients transferred with suspected fetal compromise seven of the 21 babies required delivery within two hours of arrival because of abnormal results of fetal cardiotocography. As time is required in such cases for assessment and also for stabilisation in women with pre-eclampsia some degree of the acuteness of the problems on admission becomes apparent. This point was reinforced in the woman with antepartum haemorrhage to whom three of the 12 babies who did not die were delivered by caesarean section less than 50 minutes after arrival in the hospital.

\section{MODE OF DELIVERY}

Table III shows the pronounced difference in the numbers of vaginal and operative deliveries between the two groups. The incidence of caesarean section in the group with uncomplicated preterm labour was $27 \%$, but considering the nature of the problem this was not surprising. The problems associated with the patients in group 2, however, were responsible for an incidence of caesarean section of $79 \%$. The relatively common use of the classical procedure $(14 \%$ of all caesarean sections) is noteworthy in view of its implications for future reproductive performance. Labour, delivery, and its immediate consequences generated the need for administration of 91 general anaesthetics and 30 epidurals among the 190 patients.

TABLE IV-Postpartum complications in women (group 2) transferred to Liverpool Maternity Hospital

Intensive monitoring required 17 Blood transfusion required

Pneumonia

Wound infection

Referred to renal specialists

Pneumothorax

Pefermoth to hypertensionclinic

Total
Referred to hypertension clinic haemorrhage on primary referral. Table IV gives details of these complications. In particular, women with pre-eclampsia caused considerable management problems: 17 of the 25 required intensive monitoring in a specially designed room in the delivery suite for periods of 48 hours or more. This included heavy sedation, administration of antihypertensive drugs, and the insertion of central venous lines to help assess fluid balance. Analysis of blood gas tensions, arterial cannulation, and pulse oximetry were employed as necessary. Equipment for intubation and mechanical ventilation were immediately available in the room, although these were not used for any of the patients.

The postpartum emotional stress encountered among the patients was expected, partly reflecting the high perinatal loss and neonatal morbidity associated with the reasons for referral. Four babies died during transfer: two of the mothers had been referred with uncomplicated preterm labour, one with antepartum haemorrhage (which was subsequently diagnosed as a placental abruption), and one with a rupture of a previous caesarean section scar. Only 19 mothers $(10 \%)$ were transferred either home or back to their base hospital accompanied by their babies. Thirty five mothers (18\%) were discharged after being delivered of at least one dead infant.

\section{Discussion}

From our results it is clear that in utero transfer in cases in which the only problem is threatened or established preterm labour presents few difficulties for the mothers and provides excellent facilities for dealing with any problems the neonate may develop. But the $16 \%$ of mothers delivering or being delivered within one hour of arrival in the receiving hospital, often after a long ambulance journey, remain a concern as the deliveries may possibly have been precipitated during transfer. Similarly, in cases of intrauterine compromise reservations about fetal safety during transfer must also exist as many of these vulnerable fetuses, which often have severely retarded growth, were transferred having already shown considerably abnormal features on cardiotocography.

In utero transfer poses additional problems for women with coexisting disease. In several cases mothers were transferred in far from ideal circumstances, especially those with worsening pre-eclamptic toxaemia or antepartum haemorrhage. These mothers often required urgent resuscitation or the rapid establishment of aggressive treatment with antihypertensive drugs and sedatives immediately after arrival at the hospital. The incidence of caesarean section in women with pre-eclamptic toxaemia and antepartum haemorrhage was extremely high at $86 \%$ (32 of the 37 women with a viable fetus), and the procedure inevitably generated more complications in already ill women. The results suggest that urging caution in selecting these patients for transfer is justified; the transfer itself, when monitoring of both mother and fetus is far from ideal, is an additional hazard to both.

It seems that there are two options for dealing effectively with the already ill mothers in the in utero transfer programme. The first, which we prefer, sees the compromised patients remaining in their base hospitals and delivering there. If it then proved necessary the neonate could be transferred under the long established paediatric flying squad arrangements to a neonatal intensive care unit. In addition, the mother would often be within easy reach of a high dependency or general intensive care unit within the district general hospital site.

If, however, the second option is chosen and the policy of accepting for transfer women with coexisting disease with a perceived threat to the fetus is to
Important postpartum complications were confined to those women with pre-eclampsia or antepartum 
continue then several problems need to be resolved Firstly, it may be prudent to adhere to the recommendations made in the 1979-81 confidential inquiry into maternal morbidity ${ }^{12}$ and establish one or more teams in the receiving hospitals with expertise in managing such conditions as worsening pre-eclamptic toxaemia. Advice could then be given before transfer. Secondly, the receiving hospitals must continue to encourage both medical and midwifery staff to maintain their abilities to deal with severely ill mothers who are highly dependent, as routinely accepting compromised patients will inevitably lead to an increase in the incidence of maternal morbidity.

Whichever option is chosen, however, it seems that a much fuller assessment of the risks to the mother must be undertaken before transfer. In many cases these may outweigh the risks to the fetus.

1 Chiswick ML. Perinatal referral: a time for decisions. Br.Med $\mathcal{f}$ 1982;285:83-4 2 Cooke RWI. In utero transfer to specialist centres. Arch Dis Child 1983;58 483-4.
3 Blake AM, Pollitzer MJ, Revnolds EOR. Referral of mothers and infants for intensive care. Br.Med f 1979;ii:4lt-6.

+ Modanlou HD, Dorchester W, Freeman RK, Rommal C. Perinatal transpor to a regional perinatal centre in a metropolitan area: maternal versus to a rginal perinata 70 (138:1157-64.

5 Crowley P, Lamont R, Elder MG. The obstetric care of the foetus transferred in utero. Foumal of Obstetrics and (ivnaecology 1982:2:129-33.

6 Lobb MO, Morgan MEI, Bond AP, Cooke RWI. Transfer before delivery on Merseyside: an analysis of the first 140 patients. Br $\mathcal{F}$ Obstet Gynaecol $1983 ; 90: 338-41$

7 Wood B, Catford JC, Cogswell JJ. Confidential paediatric inquiry into neonatal death in Wessex, 1981 and 1982. Br.Med $\mathcal{F} 1984 ; 288: 1206-8$.

8 Beverley D, Foote K, Howel D, Congdon P. Effect of birthplace on infants with low birth weight. Br Med f 1986;293:981-3.

9 Watkinson M, McIntosh N. Outcome of neonatal intensive care: obstetric implications for a regional service. Br f Obstet Gynaecol 1986;93:711-6.

10 Powell TG, Pharoah POD. Regional neonatal care: bias and benefit. Br Med f 1987:295:690-2.

11 Chiswick ML, Davies P, Dryburgh E, Gordon-Nesbitt D. Regional organisation of neonatal intensive care in the north-west. $\mathrm{Br} \mathrm{Med} \mathrm{f}$ 1979;ii:247-50.

12 Turnbull AC, Tindall VR, Robson G, Dawson IMP, Cloake EP, Ashlev JSA. Repurt into confidential enquiries into maternal death in England and Wales Repurt into confudential enquiries into maternal death in England and Wales
1979-1981. London: HMSO, 1986:20-1. (Report on health and social subjects No 29.)

(Accepted 21 September 1989)

\section{Monitoring and evaluating Working for Patients}

\section{Ken Judge}

Each new piece of information made available by the Department of Health about the detailed implementation of Working for Patients emphasises the magnitude of the changes facing the NHS in the run up to 1991. The passage of time since the proposals were first announced, however, has done little to assuage the fear that many of them represent a giant leap into the unknown. Many commentators, therefore, have been disappointed at the government's antagonism to a more evaluation oriented approach. There is some evidence of a growing recognition in ministers that learning by doing must be an integral part of the reform process. But there is little support in Whitehall for comprehensive monitoring and evaluation of the changes that have been set in train.

Against this background the King's Fund has decided to support independent assessments of the government's proposals. National advertisements were placed in the specialist press during the summer to encourage outline research applications from a wide variety of sources; 78 were subsequently received and considered. A short list of 13 was selected and investigated in more detail. The King's Fund has decided to invest about $\$ 500000$ over the next two to three years on five of these projects, and further consideration is being given to another two.

The five research projects, which are summarised below, will form the centrepiece of the fund's efforts to monitor and evaluate the implementation of Working for Patients. This activity will be coordinated by the King's Fund Institute and will include close observation of the forthcoming legislative process and the gathering of wider intelligence about relevant research and development activity throughout the NHS.

The King's Fund is supporting research on the following topics:

- The introduction of managed competition in one NHS region

- The development of selected budget holding general practices

- The implementation and use of clinical audit in the specialty of general medicine

- Changes in patients' and general practitioners' satisfaction with access to hospitals for "cold surgery"
- The impact of Working for Patients on elderly people.

The Fund is also considering research aimed at investigating the impact of the white paper on administrative and labour costs in hospitals and management of staffing in the NHS.

\section{MANAGED COMPETITION}

Managed competition in health cares lies at the heart of the government's future strategy for the NHS. A key assumption is that separating the purchase of health care from its provision will stimulate competition between providers so as to:

- Increase cost sensitivity

- Improve efficiency

- Encourage innovation and enterprise

- Raise quality standards.

Research by the National Association of Health Authorities aims at monitoring the introduction of managed competition in the West Midlands region over three years. The project has four main aims.

- Firstly, it will monitor changes in the scale and pattern of service provision. This will entail documenting changes in flows of patients and service patterns such as the type, volume, and location of services offered by providers

- Secondly, the research will subject the theory of managed competition to empirical test. The full effects will not become apparent over the relatively short life of the project. Nevertheless, there will be strong indications of its direction, and it will be possible to identify trends and different management approaches - Thirdly, the work of the National Association of Health Authorities will contribute to management learning and the management of change. Information on best practice and innovation on such issues as contract construction, performance evaluation, and price setting will be made available to managers and clinicians as the research progresses

- Finally, the project will develop more precise and reliable instruments and indicators to aid long term 